\title{
The Potential of Lacquer Peel Profiles and Hyperspectral Analysis for Exploration of Tailings Deposits
}

\author{
W. Nikonow ${ }^{(\bowtie)}$ and D. Rammlmair \\ Federal Institute for Geosciences and Natural Resources (BGR), \\ Hanover, Germany \\ wilhelm.nikonow@bgr.de
}

\begin{abstract}
Lacquer peel profiles are a valuable technique to preserve and study sedimentary structures and depositional features outside the field. The use of the lacquer fluid Mowiol ${ }^{\circledR}$ has shown to work well as a simple and rapid preparation technique for tailings material from a tailings heap in Copiapó, Chile. The combination of lacquer peels with 2D mapping techniques such as Hyperspectral Imaging (HSI) can provide important sedimentary information such as particle size distribution on a large scale with little effort, which becomes quantifiable due to continuous 2D information and modern image analysis. The presented relationship of element or mineral distribution with particle size can serve as a tool for targeted and more focused sampling for mineral exploration in tailings and tailings analysis in general, considering future selective mining for economic or environmental reasons.
\end{abstract}

Keywords: Lacquer profile $\cdot$ Sedimentology $\cdot$ Hyperspectral Imaging • Tailings exploration

\section{Introduction}

Creation of lacquer peels is an old, but rarely recognized technique enabling preservation of sedimentary structures of granular materials. The profiles are also known as sedimentary peels, sediment plates or lacquer profiles and are similar to the early description of soil monoliths by e.g. Voigt (1936). As a relatively simple and inexpensive technique with great possibilities in various geoscientific fields it represents a valuable method to study and preserve complex depositional processes and sedimentary textures on a scale from millimeters up to several square meters.

The general procedure is to apply the lacquer fluid on the target area, then let the fluid dry, solidify, remove the peel and fixate it on a board for transport and display. A detailed technical description of the preparation process can be found e.g. in Van Baren and Bomer (1979). The impregnation takes place due to gravity and capillary forces, which makes it possible to create vertical profiles.

The advantage of lacquer peel preparation is the possibility to preserve and transport features of interest for additional analysis on the site or in the laboratory. The combination of lacquer peels with emerging analytical techniques for 2D mapping such 
as Hyperspectral Imaging (HSI) can provide non-destructively valuable information from e.g. textural, sedimentological and geochemical analysis.

HSI is commonly used in remote sensing and finds its path into other fields of geoscience. HSI measures the reflectance of the samples in a wavelength range of, in this work, the visible and near infrared region (VIS-NIR: 400-2500 nm). It utilizes molecule - light interaction such as vibrational processes or electron energy level transitions which produce characteristic absorption features at certain wavelengths (Hunt and Salisbury 1970).

\section{Methods and Approaches}

The lacquer profiles were taken from a tailings heap in the city of Copiapó in northern Chile. According to historic aerial images it was deposited ca. 1993 on an area of ca. $230 \times 130 \mathrm{~m}$ with an approximated mass of $400.000 \mathrm{t}$ in 2018 . There is only little information about the origin of the heap, but the material is most probably from a nearby processing plant using flotation or leaching to process ore from one of the many mines in the Punta del Cobre district around Copiapó. Since the heap is not covered, it is a target for erosion by wind and rain affecting the adjacent area including the Copiapó River.

Three lacquer profiles were taken from the steep parts of the eastern and western sides, where the internal layering becomes visible and accessible. To create the profiles the polyvinyl alcohol Mowiol@ 4-88 was used. It is dissolved in hot water a day before preparation. At the site, the selected surface is scraped even and the Mowiol is applied on the surface by a spray bottle or a brush. For stabilization, several layers of Mowiol and gauze are laid on the back of the profile. Then the profiles are left to dry for about 24 h. Finally, they can be removed with a knife and, wrapped in cloth, can be transported easily. Preparation of one profile of about $30 \times 50 \mathrm{~cm}$ takes about $30 \mathrm{~min}$ excluding the time for drying. One profile was taken from the eastern side (LP1) and two profiles from the western side (LP2, LP3). Additional samples from each layer were taken next to the profiles for geochemical, particle size analysis and verification of the HSI analyses.

The dry profiles were analyzed in the laboratory with the SisuRock system from Specim. The images were taken with two push broom cameras covering the wavelength range from 400 to $2500 \mathrm{~nm}$ (VNIR and SWIR) at a spatial resolution of $875 \mu \mathrm{m}$ (SWIR) and $280 \mu \mathrm{m}$ (VNIR). The data were processed using vertical de-striping and minimum noise fraction transform.

\section{Results and Discussion}

From the tailings impoundment three lacquer profiles were prepared. The profiles were left to dry for about $24 \mathrm{~h}$ to minimize the risk of destroying structures during removal and transport. When the profiles were removed from the tailings wall, only small areas at the edges or in clay layers were lost, but overall, the texture was well preserved. 
Hyperspectral images of all profiles were obtained in the laboratory with the SisuRock system within minutes. The data show clearly the layered structure, which seems to be mostly an effect of particle size. Figure 1 shows the optical and the hyperspectral image of LP2. Layers that were differentiated optically in the field are indicated by capital letters. In the hyperspectral image areas of coarse particle size appear dark, while layers of fine particle size appear light grey or white. The data show a regression coefficient of $R^{2}=0.76$ at $860 \mathrm{~nm}$ between particle size and reflectance.

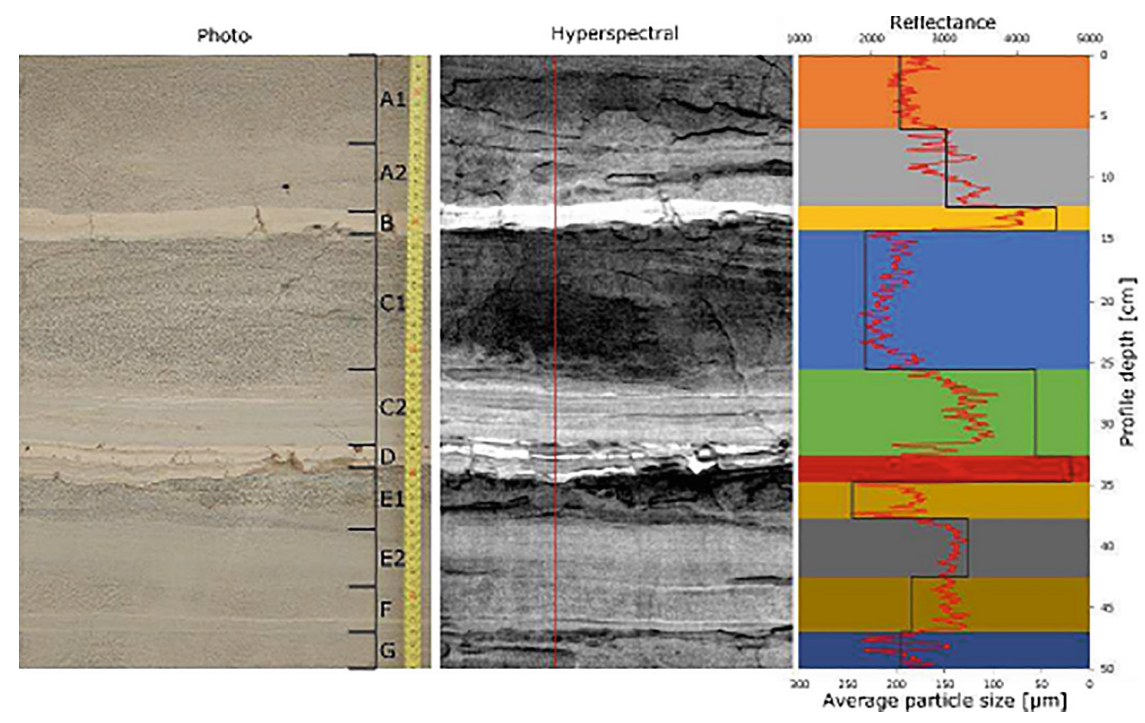

Fig. 1. Left: True color photo of the lacquer peel LP2 with layers selected for bulk sampling. Middle: Hyperspectral scan of LP2 at $860 \mathrm{~nm}$. The red line indicates the position of the reflectance profile in the right graph. Right: Distribution of reflectance (red line) at $860 \mathrm{~nm}$ and average particle size (black line) at lacquer peel LP2.

The effect of particle size on reflectance in the visible and infrared wavelength region has been studied in the literature and was described as a negative correlation (Hunt and Vincent 1968; Okin and Painter 2004; Salisbury and Hunt 1968). However, the application on and implications for tailings evaluation still have to be described. The particle size distribution is an important information for the evaluation of the economic value of tailings deposits. The extractability of e.g. Cu depends largely on the particle size of the $\mathrm{Cu}$ minerals, since flotation or heap leaching depend on the access to free mineral surfaces. The geochemical data from the additional samples analyzed by $\mathrm{XRF}$ show a possible trend of increasing $\mathrm{Cu}$ concentration with increasing particle size above $100 \mu \mathrm{m}$. These areas of interesting particle size can be identified, located and quantified with HSI. After establishing the methods in the laboratory, it could be expanded to drill cores or in-situ measurements in the field. Therefore, the combination of creating lacquer profiles and HSI and image analysis serves as a rapid and simple tool to acquire important information for targeted and more selective sampling and even evaluation of tailings material for possible selective mining. 


\section{Conclusions}

The proposed method of creating lacquer profiles has worked well on tailings material. It is a simple and rapid method to preserve sedimentary features for display and further analysis. The combination with 2D mapping techniques such as HSI provides rapidly continuous 2D information on sedimentary structures and particle size distribution on a scale from micrometer to meter. The information is quantifiable by image analysis and can be used for various geoscientific applications including sedimentology, sequential analysis and tailings exploration.

Acknowledgements. The results of this work are part of research that is funded by the German Federal Ministry of Education and Research (BMBF) within the projects SecMinStratEl (033R118B) and SecMinTec (033R186B). We thank Dominic Göricke for preparation of the lacquer profiles and Dr. Martin C. Schodlok for support with the hyperspectral data processing. We are very grateful to the reviewers for their helpful comments.

\section{References}

Hunt GR, Salisbury JW (1970) Visible and near-infrared spectra of minerals and rocks: I silicate minerals. Mod Geol 1:283-300

Hunt GR, Vincent RK (1968) The behavior of spectral features in the infrared emission from particulate surfaces of various grain sizes. J Geophys Res 73:6039-6046

Okin GS, Painter TH (2004) Effect of grain size on remotely sensed spectral reflectance of sandy desert surfaces. Remote Sens Environ 89:272-280

Salisbury JW, Hunt GR (1968) Martian surface materials: effect of particle size on spectral behavior. Science 161:365-366

Van Baren J, Bomer W (1979) Procedures for the collection and preservation of soil profiles. International soil museum

Voigt E (1936) Die Lackfilmmethode, ihre Bedeutung und Anwendung in der Paläontologie, Sedimentpetrographie und Bodenkunde. Zeitschrift der deutschen geologischen Gesellschaft 88:272-292

Open Access This chapter is licensed under the terms of the Creative Commons Attribution 4.0 International License (http://creativecommons.org/licenses/by/4.0/), which permits use, sharing, adaptation, distribution and reproduction in any medium or format, as long as you give appropriate credit to the original author(s) and the source, provide a link to the Creative Commons license and indicate if changes were made.

The images or other third party material in this chapter are included in the chapter's Creative Commons license, unless indicated otherwise in a credit line to the material. If material is not included in the chapter's Creative Commons license and your intended use is not permitted by statutory regulation or exceeds the permitted use, you will need to obtain permission directly from the copyright holder.

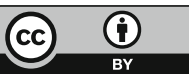

